Araştırma Makalesi / Research Article

\title{
Ekizköy (Muğla-Milas) Erken-Orta Miyosen Kömürlerinin Organik Jeokimyası ve Paleoiklim Şartları
}

\author{
Organic Geochemistry and Paleoclimate Conditions of the Early-Middle Miocene Coals at the Ekizköy \\ (Muğla-Milas)
}

\section{Fatma HOŞ ÇEBİ}

Karadeniz Teknik Üniversitesi, Mühendislik Fakültesi, Jeoloji Mühendisliği Bölümü, TRABZON

$\begin{array}{lll}\text { Geliş (received) } & : & \text { 03 Haziran (June) } 2016 \\ \text { Düzeltme (revised) } & : & 27 \text { Temmuz (July) } 2016 \\ \text { Kabul (accepted) } & : & \text { 01 Ağustos (August) } 2016\end{array}$

\section{ÖZ}

Bu çalışmada, Muğla ili Milas ilçesinin güneydoğusunda yer alan Ekizköy sahası kömürlerinin organik jeokimyasal özellikleri, çökelme ortamı ve paleoiklim şartları ortaya konmuştur. Ekizköy kömürlerinin toplam organik karbon (TOK) içeriğinin ortalama \% 46.24, Hİ (Hidrojen İndeksi) değerlerinin ortalama $152.88 \mathrm{mgHK} / \mathrm{gTOK}$ ve Oksijen İndeksi (Oİ) değerlerinin ise ortalama $76.63 \mathrm{mgCO}_{2} / \mathrm{gTOK}$ olduğu görülmüştür. $\mathrm{Bu}$ değerler turba ortamındaki yarı oksik ortam şartlarını ve ancak gaz türetebilecek organik maddeyi yansıtmaktadır. Hİ- $\mathrm{T}_{\max } \mathrm{S}_{2}$-TOK sınıflama diyagramlarında organik maddenin Tip II ve Tip III kerojenden oluştuğu görülmüştür. Gaz kromatogramlarında, yüksek ve tek karbon numaralı $n$-alkanların baskın olduğu ve az miktarda da algal katkının olduğu bir dağılım gözlenmektedir. Seçilen M-4 ve M-8 nolu örnekler için karbon tercih indeksleri sırasıyla $\mathrm{CPI}_{22-30} 2.8,2.4$ ve $\mathrm{CPI}_{26-28} 3.2$, 2.8 olarak hesaplanmıştır. Karasal/sucul hidrokarbon oranları TAR $_{H C}$ (Terrigenous/aquatic ratio) 13 ve 28 olarak hesaplanmış olup, bu değerler yüksek karbon numaralı $n$-alkanların baskın olduğu karasal organik maddeyi yansıtmaktadır. M-4 ve M-8 örneklerinin alındığı seviyelerde CPI, $\mathrm{TAR}_{H C}, \mathrm{ACL}, \mathrm{Q}_{\text {wood/grass }}, \mathrm{Q}_{\text {wood/plant }}$ ve $\mathrm{Q}_{\text {grassplant }}$ oranlarına göre, ağaçsı organik maddenin baskın, iklimin göreceli olarak nemli ve yarı tropik olduğu, ancak M-8 nolu örneğin alındığı periyotta iklimin M-4 nolu örneğin alındığı periyoda nazaran daha nemli olduğu ve daha yüksek su tablasının bulunduğu, buna bağlı olarak da sucul bitki açısından daha zengin olduğu söylenebilir.

Anahtar Kelimeler: GC, $n$-alkan, Paleoiklim, Piroliz.

\section{ABSTRACT}

In this study, organic geochemistry, depositional environments and paleo-climatic conditions of Ekizköy coals located southeast of Muğla (Milas) were investigated. The average values of total organic 
Hoş Çebi

carbon content (TOC) of the coal (46.24\%), HI (152.88 $\mathrm{mgHK} / \mathrm{gTOC})$ and OI (76.63 $\left.\mathrm{mgCO}_{2} / \mathrm{gTOC}\right)$ show that the depositional environment of peat deposits is suboxic. According to HI-T $T_{\max } S_{2}$-TOC classification diagrams, the organic matter is composed of Type II and Type III kerogen. In gas chromatographs, n-alkanes with high, mostly single-numbered carbons are dominated and they are associated with a slight algal contribution. CPI ${ }_{22-30}$ is calculated as 2.8, and 2.4. CPI ${ }_{26-28}$ is calculated as 3.2, and 2.8. Terrigenous/ aquatic ratio $\left(T A R_{H C}\right)$ is very high, computed as 13 and 22. These values indicate a dominance of highcarbon numbered n-alkanes, meaning the presence of terrestrial organic matter. The CPI, TAR ${ }_{H C} A C L$, $Q_{\text {wood/grass }} Q_{\text {woodplant }}$ ve $Q_{\text {grass/plant }}$ values of the sample $M-4$ show that woody plants were the dominant vegetation in the peat mire and the climate was relatively wet and subtrophic. However, these values of the sample M-8 show warmer climate, higher water table and also contain further aquatic vegetation than the values of M-4 sample.

Keywords: GC, n-alkanes, Paleoclimate, Pyrolysis.

\section{GİRIŞ}

Muğla'nın Milas ilçesinde Sekköy, Ekizköy, Çakıralan (Belentepe) ve Hüsamlar sahalarında linyit işletmeleri bulunmakta olup çalışma konusunu oluşturan linyit örnekleri Ekizköy sahasına aittir. Ekizköy linyit (MuğlaMilas) sahası Güneybatı Anadolu'da bulunan Muğla iline bağlı Milas ilçesinin güneyinde yer almaktadır (Şekil 1). Literatürde, Milas kömürlerine ilişkin kimyasal, petrografik, palinolojik ve kapsamlı inorganik jeokimyasal çalışmalar yapılmış olup, organik jeokimyasal özellikleriyle ilgili bir çalışmaya ve bu özelliklerden yararlanılarak yapılmış bir paleoiklim yorumlamasına rastlanmamıştır. Sahada yapılan çalışmalardan bazıları; Yiğitel, 1979; Atalay, 1980; Göktaş, 1982; Gökmen vd., 1993; Görür vd., 1995; Querol vd., 1999; Kayseri Özer vd., 2014; Kayseri-Özer, 2014'tür. Muğla-Milas civarındaki sahaların Türkiye'deki en kaliteli linyit havzalarından olduğu ve Milas havzasında yaklaşık olarak 328.1 milyon ton civarında linyit olduğu belirlenmiştir (Gökmen vd., 1993). Muğla - Milas sahalarında üretilen kömürler bölgedeki üç termik santrali (Yatağan, Kemerköy ve Yeniköy Termik Santralleri) beslemektedir. Kullanılan kömürle, Yatağan Termik Santrali'nden yıllık 630 MW, Kemerköy Termik Santrali'nden 630 MW ve Yeniköy Termik Santrali'nden 420 MW enerji elde edilmektedir (Querol vd., 1999). Muğla'nın Milas ve Yatağan ilçelerindeki havzalardan her y1l yaklaşık 10 milyon ton kömür çıkarıldı ğı tahmin edilmektedir (Querol vd., 1999). Bu havzalardan çıkarılan kömürlerin, istihdama, ülke ekonomisine katkıs1 ve termik santrallere sağladığı hammadde göz önünde bulundurulduğunda, daha uzun yıllar işletilmeye devam edeceği gözlenmektedir. Ekizköy sahasında kömür kalınlıkları 2.8 ile $26.2 \mathrm{~m}$ arasında değişmekte olup, 53.3 milyon tonu açı işletme, 37.6 milyon tonu da kapalı işletme ile çıkarılabilecek olmak üzere toplam 90.9 milyon ton linyit rezervi bulunmaktadır (Gökmen vd., 1993).

Bu çalışmada, Türkiye ekonomisinde önemli bir yere sahip olan Ekizköy sahası linyitlerinin organik madde miktarı-tipi-olgunluğu, hidrokarbon potansiyeli ve çökelme ortamı gibi 
özelliklerinin, organik jeokimyasal analizlerden elde edilen çeşitli parametreler vasıtasıyla ortaya konulması amaçlanmıştır.

\section{GENEL JEOLOJI}

Muğla havzasında, temel kayaçları, altta Menderes Masifi'ne ait Paleozoyik yaşlı şist, gnays ve rekristalize kireçtaşları, üstte ise Likya
Napı'na ait kireçtaşı bindirmeleri oluşturmaktadır (Şekil 1). Bunların üzerinde Alatepe, Turgut, Sekköy, Yatağan, Milet formasyonlarından oluşan Miyosen yaşlı çökeller bulunmaktadır. Linyit; Alatepe, Turgut, Sekköy formasyonları içerisinde yer almaktadır (Şekil 2). Havzada en genç birimleri Kuvaterner yaşlı çökeller oluşturmaktadır (Querol vd., 1999).
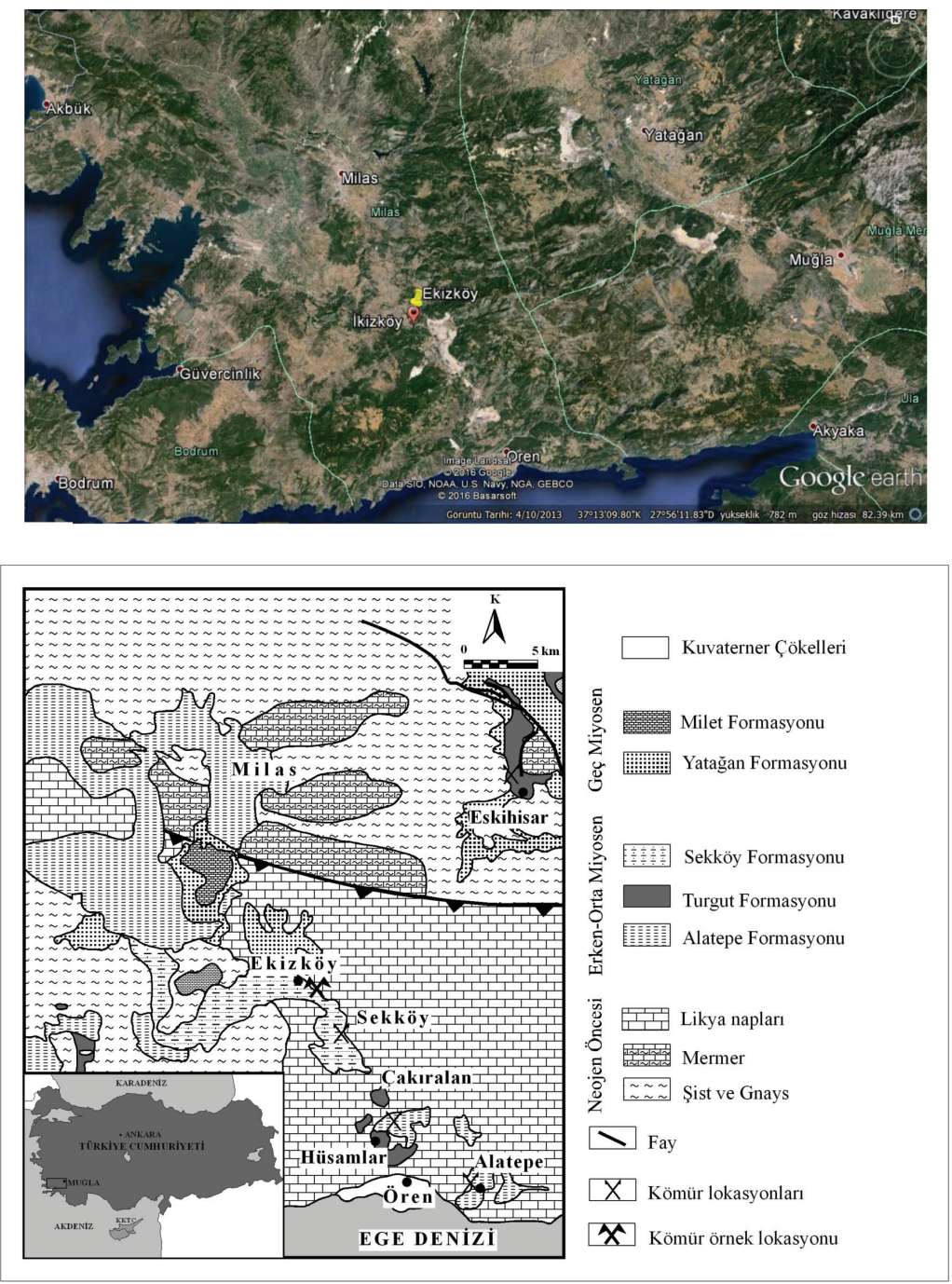

Şekil 1. Ekizköy (Milas-Muğla) kömür sahasının yer bulduru ve jeolojik haritası (Querol vd.,1999'dan değiştirilerek).

Figure 1. The location and geological map of the Ekizköy (Milas-Muğla) coalfield (modified from Querol et al., 1999). 
Hoş Çebi

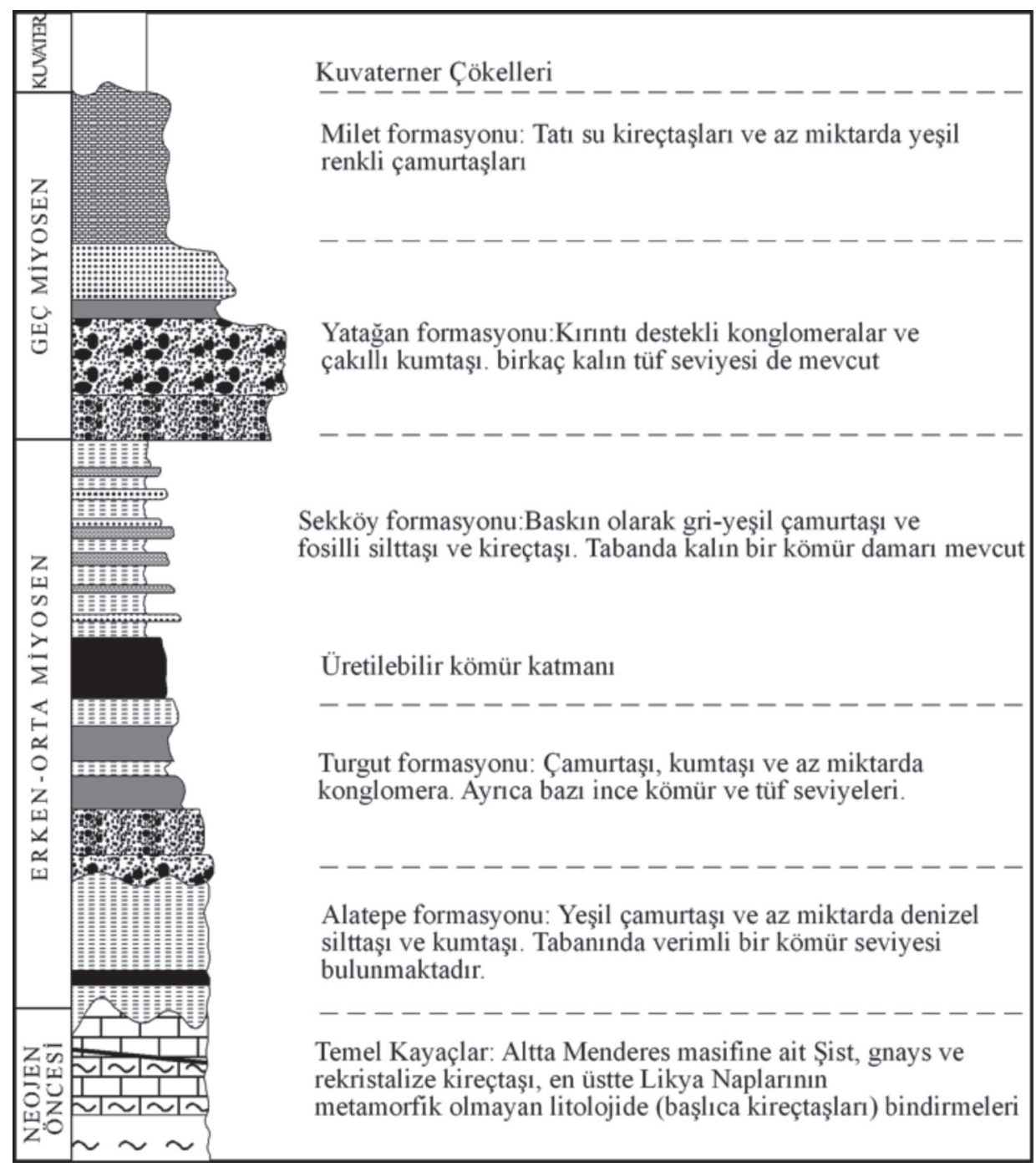

Şekil 2. Miyosen Muğla Havzası'nın stratigrafik dikme kesiti (Querol vd., 1999'dan değiştirilerek).

Figure 2. The Stratigraphic columnar section of the Miocene Muğla Basin (modified from Querol et al., 1999).

Sahada bulunan Miyosen yaşlı formasyonlar yaşlıdan gence doğru özetlenmiştir: Şist, gnays ve rekristalize kireçtaşlarından oluşan taban kayacı Muğla Havzası'nın en yaşlı birimini (Neojen öncesi) oluşturmaktadır. Alatepe formasyonu uyumsuz olarak Likya naplarının üzerinde bulunmaktadır. Yeşil renkli çamurtaşı, az miktarda denizel silttaşı ve kumtaşından oluşan Alatepe formasyonunun tabanında yatay olarak çökelmiş verimli kömür seviyeleri yer almaktadır (Görür vd., 1995). Kömürlü seviyeler 100 ve 130 cm kalınlığında iki damar halinde bulunmaktadır. Alatepe formasyonu, üstte Turgut formasyonuyla uyumlu, altta da taban kayası üzerine uyumsuz olarak gelmektedir. Alatepe formasyonunda bulunan bentik foraminiferlerden yapılan yaş tayininde formasyonun yaşı Erken Miyosen olarak belirlenmiş, Alatepe formasyonunun 
oluşum ortamının fluvyal delta ortamı olduğu belirtilmiştir (Görür vd., 1995).

Turgut formasyonu çamurtaş1, kumtaş1 ve az miktarda da konglomeradan oluşmakta olup, içerisinde ince kömür ve tüf seviyelerini barındırmaktadır. Formasyonun kalınlığının birkaç metreden birkaç yüz metreye kadar olabileceği belirtilmiştir. Turgut formasyonu, altta Alatepe formasyonuyla, üstte verimli kömür damarıyla ve Sekköy formasyonuyla uyumludur. Orta Miyosen yaşlı Sekköy formasyonu altına uyumlu olarak gelmesi nedeniyle yaşı Erken - Orta Miyosen olarak verilmiştir. Turgut formasyonunun oluşum koşulları göl ve nehir ortamları olarak belirlenmiştir (Gökmen, 1993).

Sekköy formasyonu, yaklaşı $20 \mathrm{~m}$ kalınlığındaki linyitli seviyelerin üzerinde yer alan ve altta ortalama tabaka kalınlığ 1 yaklaşık $1 \mathrm{~m}$ olan grimsi ve zeytin yeşili renkli kompakt marnlarla, üste doğru ise laminalı marn, ince kireçtaşı ve kiltaşı ardalanması şeklinde bir istifle temsil edilir. Bunun yanı sira, bu formasyon havza kenarlarında kireçtaşı ve konglomeralardan oluşan bir detritik fasiyesi ve Yatağan formasyonu ile kendi arasında yer alan yeterince pekişmemiş kiltaşı ve silttaşı ardalanmasından meydana gelen bir geçiş fasiyesini içermektedir (Querol vd., 1999). Sekköy formasyonunun taban kesimlerinde kalın kömür damarları bulunmaktadır. Sekköy formasyonu üstte Geç Miyosen yaşlı Yatağan formasyonuyla altta ise Erken-Orta Miyosen yaşlı Turgut formasyonuyla uyumludur (Yiğitel, 1979; Atalay, 1980). Yaş1 Orta Miyosen'dir (Yiğitel, 1979; Atalay, 1980). Sekköy formasyonunun oluşum ortamı, Atalay (1980) tarafından göl ortamı olarak belirlenmiştir.

Yatağan formasyonu Üst Miyosen yaşlı olup, egemen litolojisi kırmızımsı kahverengi, orta ve kaba taneli kumtaşlarıdır ve üst kesimlerde yer yer mercek şeklindeki çakıltaşları, konglomeralar ve tüfit katkıları da yer almaktadır (Atalay, 1980). Yatağan formasyonu altında Sekköy formasyonu, üzerinde ise Milet formasyonu uyumlu olarak çökelmiştir. Yatağan formasyonu içerisinde bol miktarda memeli fosilleri bulunmuştur (Querol vd., 1999). Yatağan formasyonunun Atalay (1980) tarafindan göl ortamlarında oluştuğu belirlenmiştir.

Milet formasyonu kireçtaşı, mermer ve killi kireçtaşı ara katmanları kapsar. Tabanında yer yer 1-2 metrelik, linyit ara katmanlı silttaşı düzeyi izlenmiştir (Querol vd., 1999). Formasyonun kalınlığ1 yaklaşık 140 metredir. Alt sınırında, uyumlu bulunduğu Yatağan formasyonu, üst sinırında ise uyumsuz olarak gelen Kuvaterner çökelleri bulunmaktadır. Atalay (1980), yapmış olduğu çalışmalar sonucunda, mermer ve kireçtaşları üzerlerinde gastrapod kavkılarına ve memeli fosillerine rastlamış ve formasyonunun göl ortamlarının yükselmesi sonucu oluştuğunu belirtmiştir.

Kuvaterner çökellerini, kum, kil, çakıllardan oluşan kötü boylanmalı malzeme oluşturmaktadır.

\section{MATERYAL VE METOT}

Rock-Eval/TOK analizleri, MilasEkizköy sahasına ait açık işletme sahasından sistematik olarak alınan 8 kömür örneği üzerinde gerçekleştirilmiştir (Şekil 3). Seçilen iki örnek için, (M-4, M-8) petrografik tanımlamalar, vitrinit yansıması ölçümleri ve GC analizleri yapılmış olup tüm analizler Türkiye Petrolleri (TP) Jeokimya Laboratuvarı'nda gerçekleştirilmiştir. 
Hoş Çebi

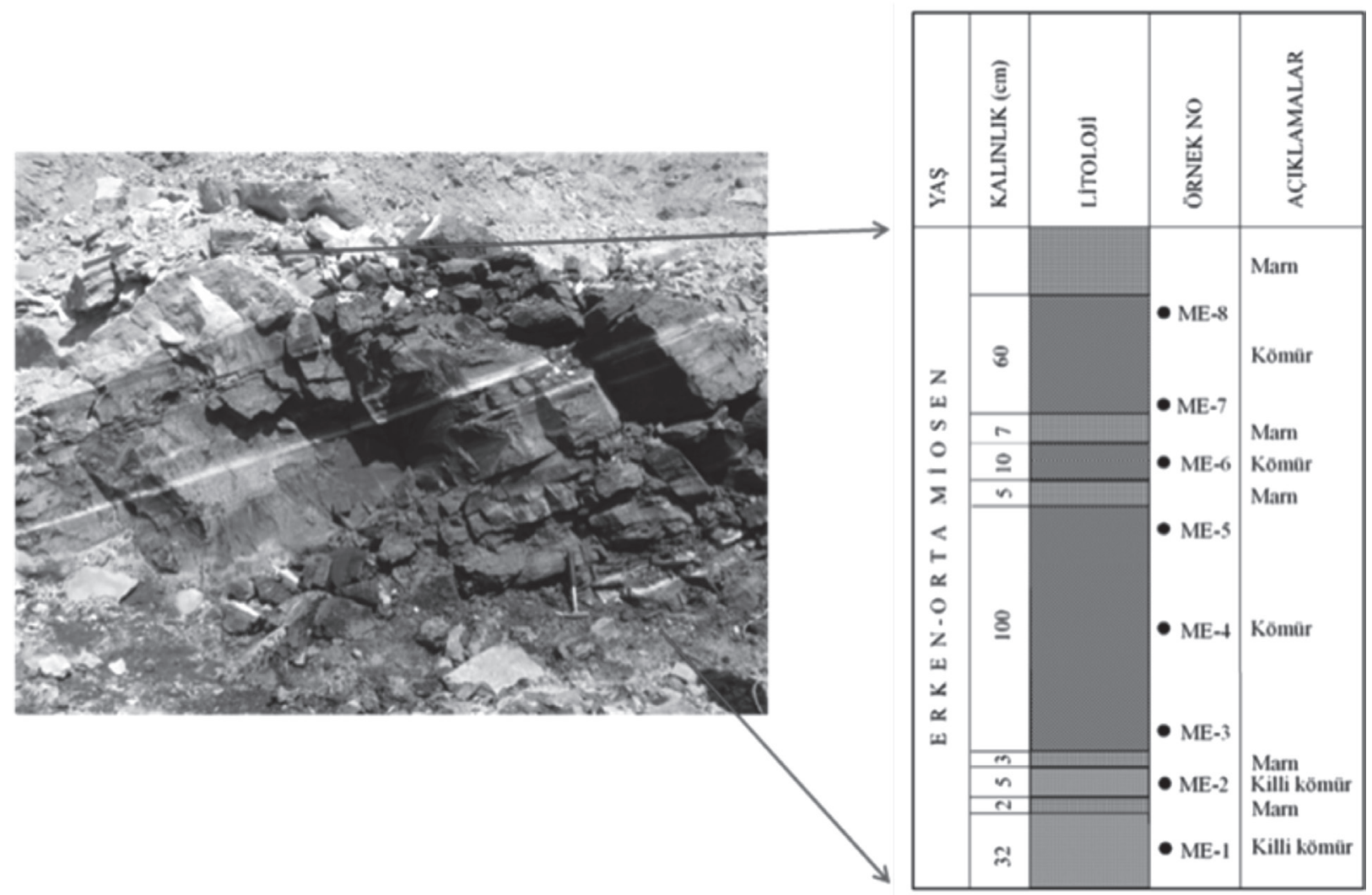

Şekil 3. Açık işletme sahasının fotoğrafı ve çalışma alanından alınan kömür örneklerinin lokasyonları.

Figure 3. The photograph of open pit area and the locations of the coal samples taken from the study area.

\section{TOK ve Rock Eval Piroliz Analizleri}

Piroliz ve TOK analizleri Rock Eval-6 (RE6) piroliz cihazı kullanılarak gerçekleştirilmiştir. TOK değerleri cihazın içerdiği bir TOK modülü ile otomatik olarak hesaplanmıştır.

\section{Gaz Kromatografi (GC) Analizi}

Gaz kromatografi analizi petrol ve bitüm örnekleri içerisindeki hidrokarbon bileşiklerinin genel olarak dağılımlarını görmek amacıyla yapılır. $\mathrm{Bu}$ analiz yöntemiyle, doygun hidrokarbon bileşenleri, bir flame fotometrik dedektör (FPD) ve bir flame ionization dedektör (FID) ile donatılmış bir Varian 3400 gaz kromatografi kullanılarak analiz edilmiştir. Kolona uygulanan sicaklık programı ile kolona verilen örnek içerisindeki moleküllerin kaynama noktalarının farklı olmasından dolayı ayrılma sağlanmaktadır. Kolon içerisinde ayrılan moleküller dedektör bölümünde ölçülerek, bilgiler sinyaller halinde bilgisayara ulaşır ve gaz kromatogramlar elde edilir. GC analizi sonunda elde edilen kromatogramlardaki pik dağılımları ve boylarına bakılarak organik maddenin tipi, olgunluğu, çökelme ortamı ve paleoiklim hakkında bilgi sağlanır ve yorumlar yapılabilir. 


\section{Vitrinit Yansıması Analizi}

Örneklerin rastgele vitrinit yansımas1 ölçümleri, yăg immersiyonunda $\left(\mathrm{R}_{\mathrm{o}} \%\right)$, beyaz 1şık kullanılarak, ICCP (1998), ISO 74045 (2009) 'a göre Windows tabanlı MSP200 programı ile Leica DM 2500P tip mikroskop kullanılarak gerçekleştirilmiştir.

\section{SONUÇLAR VE TARTIŞMA}

\section{TOK ve Rock-Eval Analizleri}

Ekizköy (Muğla-Milas) sahasına ait örneklere ilişkin TOK değerleri \% 44.11 ve \% 48.23 arasında değişmekte olup, ortalama \% 46.24 olarak hesaplanmıştır (Çizelge 1). RockEval analizlerinden hesaplanan Hİ (Hidrojen İndeksi) değeri ortalama $152.88 \mathrm{mgHK} / \mathrm{gTOK}$, Oİ (Oksijen İndeksi) değeri ise $76.63 \mathrm{mgCO}_{2} /$ gTOK'tur. Saha kömürlerinin ortalama $T_{\max }$ değerleri $420.75 \mathrm{C}^{\circ}$ ile, olgunlaşmamış organik maddeyi işaret etmektedir. $\mathrm{S}_{2} / \mathrm{S}_{3}$ kerojen tipi parametresi ortalama 2 olarak hesaplanmıştır. Ortalama potansiyel ürün değeri (PÜ) 73.02 $\mathrm{mgHK} /$ gkaya ve ortalama üretim indeksi (ÜI) 0.03 olarak hesaplanmıştır. 0.1 'den küçük bir üretim indeksi değeri olgunlaşmamış organik maddeyi göstermektedir (Merrill, 1991).

\begin{tabular}{|c|c|c|c|c|c|c|c|c|c|c|}
\hline & $\underline{e}$ & $\begin{array}{l}n \\
2 \\
\infty \\
n\end{array}$ & $\begin{array}{l}\infty \\
2 \\
\dot{m}\end{array}$ & $\begin{array}{l}f \\
\dot{\infty} \\
\infty \\
m\end{array}$ & $\begin{array}{l}\infty \\
\infty \\
\infty \\
\infty \\
\infty\end{array}$ & $\begin{array}{l}\stackrel{a}{\infty} \\
\dot{m}\end{array}$ & ọ. & $\begin{array}{c}0 \\
\infty \\
\infty \\
n\end{array}$ & $\frac{I}{m}$ & ले \\
\hline & 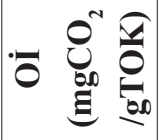 & $\stackrel{\infty}{r}$ & $\mathbb{N}$ & $\infty$ & 8 & $\cong$ & $\infty$ & $\infty$ & 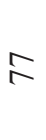 & فํ. \\
\hline & 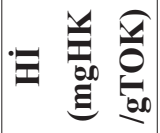 & $\stackrel{8}{-}$ & $\stackrel{\infty}{n}$ & $\stackrel{\imath}{n}$ & ป & $\sqrt{I}$ & ले & $\stackrel{ \pm}{=}$ & $\stackrel{\infty}{I}$ & $\begin{array}{l}\infty \\
\infty \\
i \\
\\
\end{array}$ \\
\hline & $\simeq$ ¿ & & & & $\bar{n}$ & & & & సু & \\
\hline & 泀 & $\frac{F}{F}$ & $\stackrel{\infty}{\mathcal{F}}$ & $\stackrel{\vartheta}{\ni}$ & $\stackrel{\infty}{\stackrel{9}{+}}$ & $\vec{\Im}$ & $\stackrel{2}{f}$ & $\overrightarrow{\stackrel{F}{f}}$ & $\widehat{\Im}$ & $\begin{array}{l}n \\
\stackrel{y}{q} \\
\stackrel{y}{q}\end{array}$ \\
\hline & 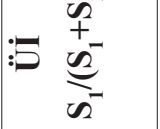 & $\hat{0}$ & $\hat{o}$ & Oे & on & $\tilde{0}$ & $\tilde{O}$ & $\begin{array}{l}\tilde{O} \\
\dot{0}\end{array}$ & $\stackrel{n}{0}$ & $\stackrel{0}{0}$ \\
\hline & 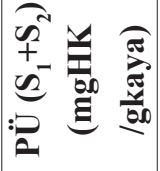 & $\begin{array}{l}\infty \\
0 \\
\infty \\
i\end{array}$ & $\begin{array}{l}\infty \\
\stackrel{\infty}{\infty} \\
\infty \\
\infty\end{array}$ & $\begin{array}{l}\hat{\sigma} \\
\dot{+}\end{array}$ & $\begin{array}{l}\tilde{6} \\
\dot{8} \\
0\end{array}$ & $\begin{array}{l}+ \\
\dot{\infty}\end{array}$ & $\begin{array}{l}\mathcal{N} \\
\infty \\
\mathbb{U}\end{array}$ & $\begin{array}{l}0 \\
\infty \\
\dot{\sigma} \\
0\end{array}$ & $\begin{array}{l}\hat{\sigma} \\
\dot{+}\end{array}$ & $\begin{array}{l}\tilde{\sigma} \\
\stackrel{n}{R}\end{array}$ \\
\hline 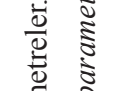 & $\frac{\infty^{m}}{\omega^{n}}$ & $\stackrel{t}{0}$ & $\frac{\infty}{i}$ & $\stackrel{+}{g}$ & $\hat{\sigma}$ & $\begin{array}{l}n \\
\tilde{n} \\
i\end{array}$ & $\stackrel{n}{n}$ & $\stackrel{\sigma}{-}$ & 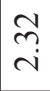 & $N$ \\
\hline 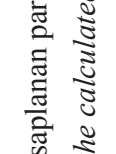 & 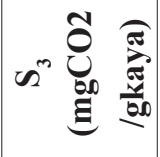 & $\frac{1}{n}$ & $\begin{array}{l}\sigma \\
\dot{j} \\
\dot{m}\end{array}$ & $\frac{a}{n}$ & $\begin{array}{l}\infty \\
\infty \\
\grave{\lambda}\end{array}$ & $\begin{array}{c}\mathbb{N} \\
\dot{f} \\
\dot{m}\end{array}$ & $\begin{array}{l}\hat{n} \\
\infty \\
\infty\end{array}$ & $\begin{array}{l}2 \\
\infty \\
i \\
m\end{array}$ & $\begin{array}{l}0 \\
\cdots \\
\dot{n} \\
m\end{array}$ & $\begin{array}{l}? \\
\text { लें }\end{array}$ \\
\hline 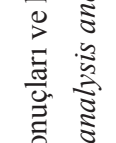 & 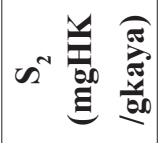 & $\frac{n}{2}$ & $\frac{7}{\circ}$ & 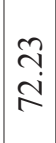 & $\stackrel{\hat{n}}{i n}$ & $\mid \vec{F}$ & $\stackrel{m}{6}$ & $\begin{array}{l}0 \\
0 \\
0 \\
0\end{array}$ & $\frac{\hat{\sigma}}{\infty}$ & $\stackrel{\infty}{\infty}$ \\
\hline 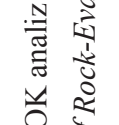 & 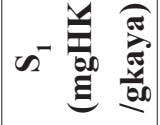 & $\stackrel{n}{n}$ & $\frac{\Delta}{i}$ & $\stackrel{+}{\infty}$ & $\begin{array}{l}n \\
\infty \\
i \\
i\end{array}$ & $\begin{array}{l}\mathfrak{g} \\
i \\
i\end{array} \mid$ & $\stackrel{n}{?}$ & $\stackrel{0}{?}$ & $\stackrel{+}{i}$ & $\frac{\infty}{i}$ \\
\hline 离 & $\stackrel{\vartheta}{\varrho}$ & ก̃ & $\begin{array}{l}\tilde{n} \\
\infty \\
+\end{array}$ & 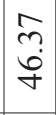 & $\begin{array}{l}\hat{n} \\
\ddot{y}\end{array}$ & 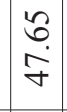 & F & $\begin{array}{l}\stackrel{\Upsilon}{\dot{f}} \\
\dot{f}\end{array}$ & $\begin{array}{l}\infty \\
\infty \\
i \\
\forall\end{array}$ & 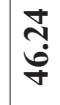 \\
\hline 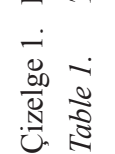 & $\stackrel{y}{\stackrel{u}{\Xi}}$ & $\stackrel{I}{\Sigma}$ & $\stackrel{N}{\Sigma}$ & $\stackrel{m}{\Sigma}$ & $\sum_{\Sigma}^{+}$ & $\stackrel{n}{n}$ & $\sum^{1}$ & I & $\sum_{i}^{\infty}$ & 吾 \\
\hline
\end{tabular}


Hoş Çebi

\section{Moleküler Bileşim}

\section{n-Alkanlar ve izoprenoidler}

GC analiz sonuçlarına gore M-4 nolu örnek için n-alkanlar $\mathrm{C}_{12}-\mathrm{C}_{35}$ aralığında, M-8 nolu örnek için ise $\mathrm{C}_{19}-\mathrm{C}_{32}$ aralığında kaydedilmişlerdir (Şekil 4 ve 5). Kromatogramlarda yüksek ve tek numaralı $n$-alkanlar baskındır. Uzun zincirli $n$-alkanların kısa zincirli $n$-alkanlara göre baskın olmas1, olgun olmayan kömürlerde yüksek karasal bitkilerden (Wang ve Simoneit, 1990; Stout, 1992; Zhang vd., 1993; Petersen vd., 2001; Bechtel vd., 2003) ve özellikle kütiküler mumlardan (Eglinton ve Hamilton, 1967) oluşan organik maddelerden kaynaklanmaktadır. M-4 nolu örneğin GC kromatogramında, karasal organik maddenin baskınlığında, zayıf algalbakteriyel $\left(<\mathrm{C}_{20}\right)$ katkının da olduğu bir dağılım gözlenmektedir. Ayrıca örneklere ait gaz kromatogramında görülen hörgüç [Unresolved Complex Mixture (UCM)], organik maddenin düşük olgunluğunu göstermektedir (Tissot ve Welte, 1984; Peters ve Moldowan, 1993; Hunt, 1995). Önceki çalışmalarda, Muğla kömürlerinin oluşumu esnasında yüksek bakteriyel aktivite ve yüksek $\mathrm{pH}$ şartlarından dolayı doku koruma indeksinin oldukça düşük olduğu tespit edilmiştir (Querol vd., 1999).

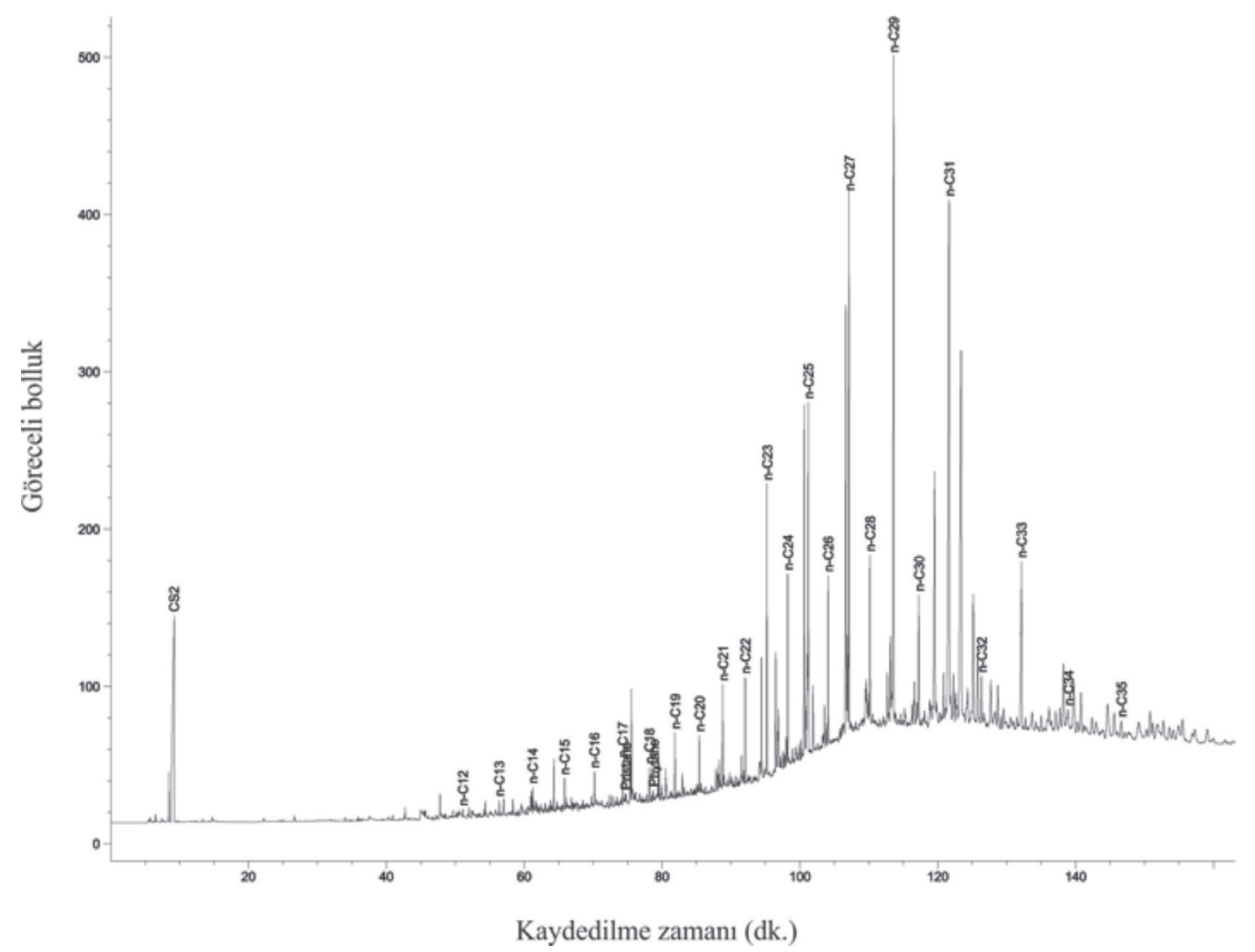

Şekil 4. M-4 nolu örneğin gaz kromatogramı.

Figure 4. Gas chromatogram of the M-4 coal sample. 


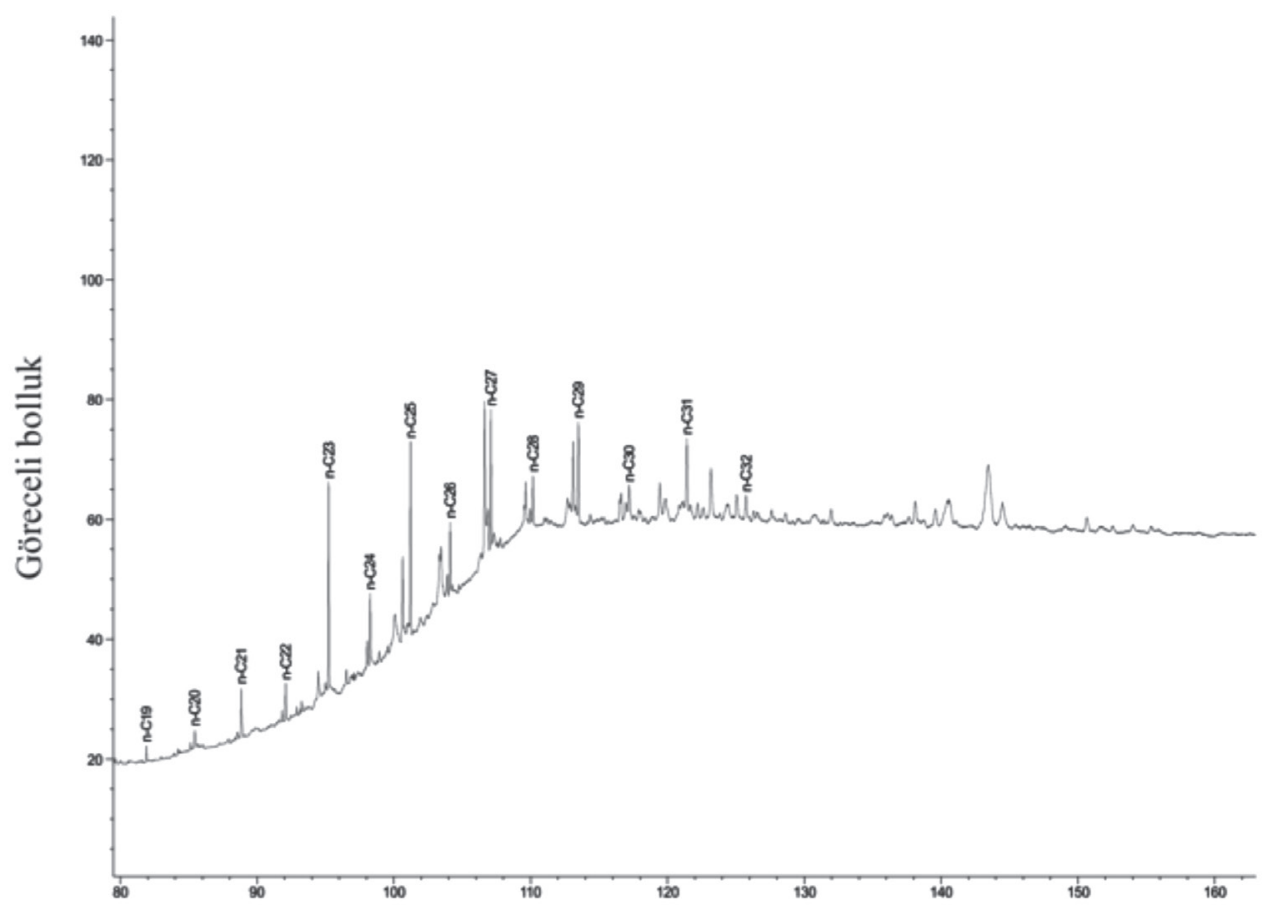

Kaydedilme zamanı(dk.)

Şekil 5. M-8 nolu örneğin gaz kromatogramı.

Figure 5. Gas chromatogram of the M-8 coal sample.

Yüksek $\mathrm{Pr} / \mathrm{Ph}$ oranı, çökelme ortamındaki oksijenli ortam şartlarını ve damarlı bitkilerin katkısını işaret etmektedir. Bu oran kömürlerde genellikle 1'den büyük değerler verir ( Korkmaz ve Kara Gülbay, 2007; Yalçın Erik ve Ay, 2010; Yalçın Erik ve Sancar, 2010; Yalçın Erik ve Ay, 2013; Hoş-Çebi ve Korkmaz, 2013; KaraGülbay, 2015; Yalçın Erik, 2016). Düşük termal olgunluktaki örneklerde $\mathrm{Pr} / \mathrm{Ph}$ oranlarının paleoortamı tanımlamada kullanılması önerilmemektedir (Volkman, 1986). Kaynak sedimanların redoks potansiyeli üzerindeki $\mathrm{Pr} /$ $\mathrm{Ph}$ oranlarından yapilan ortamsal yorumlar, diğer jeokimyasal veriler ve jeolojik bilgilerle desteklenmelidir. Örneğin; 1'den küçük $\mathrm{Pr} / \mathrm{Ph}$ oranı yüksek sülfür ve yüksek $\mathrm{C}_{35}$ homohopan indeksi anoksik şartlarda oluşan tipik bir kaynak kayayı işaret eder (Walters ve Cassa, 1985). Ekizköy sahasının önceki çalışmalardaki ölçülen toplam \% S değeri ortalama 4.2 olarak tespit edilmiştir (Querol vd., 1999). M-8 nolu örneğe ait gaz kromatogramında izoprenoidlerden $\mathrm{C}_{19}$ karbonlu ve oksitleyici ortam belirteci olan Pristan (Pr) ve $\mathrm{C}_{20}$ karbonlu ve indirgeyici ortam belirteci olan Fitan $(\mathrm{Ph})$ kaydedilmediği için $\mathrm{Pr} /$ $\mathrm{Ph}$ ve $\mathrm{Pr} / \mathrm{n}-\mathrm{C}_{17}$ oranları tespit edilememiştir. M-4 nolu örnek için $\mathrm{Pr} / \mathrm{Ph}, \mathrm{Pr} / \mathrm{C}_{17}, \mathrm{Ph} / \mathrm{C}_{18}$ oranları kromatogramdan sirasiyla $0.9,0.2$ ve 0.3 olarak hesaplanmıştır. $\mathrm{Pr} / \mathrm{Ph}$ ve $\% \mathrm{~S}$ değerleri dikkate alındığında Ekizköy kömürlerinin yarı oksik şartlar altında oluştuğu söylenebilir. 
Hoş Çebi

Milas-Ekizköy kömürlerinin CPI, TAR ${ }_{\mathrm{HC}}$, $\mathbf{P}_{\text {wax }}, \mathbf{P}_{\mathrm{aq}}, \mathrm{ACL}$ değerleri ve paleoiklim şartları

$\mathrm{C}_{26}-\mathrm{C}_{28}$ aralığında hesaplanan $\mathrm{CPI}_{1}$ değerleri M-4 ve M-8 örnekleri için sırasıyla 3.2 ve 1.9 olup, $\mathrm{C}_{22}-\mathrm{C}_{30}$ aralığında hesaplanan $\mathrm{CPI}_{2}$ değerleri 2.8 ve 2.4'tür (Çizelge 2) (Peters vd., 2005). Yüksek CPI değerleri organik maddenin çökelme ortamındaki kuru ve soğuk paleoikimi yansıtmakla birlikte, tek karbon numaralı $n$-alkanların çift karbon numaralı n-alkanlara olan baskınlığını da göstermektedir (Waples, 1985; Xie vd., 2004; Zhou vd., 2005).

$\mathrm{TAR}_{H C}$ (Terrigenous/Aquatic Ratio) indeksi karasal organik maddeden türeyen $n$-alkanların, sucul alglerden türeyen $n$-alkanlara oranını yansitmaktadır (Cranwell vd., 1987; Goossens vd., 1989; Meyers ve Ishiwatari, 1993). TAR ${ }_{H C}$ indeks değeri Ekizköy linyit örnekleri (M-4, M-8) için sırasıyla 13 ve 22 gibi oldukça yüksek değerlerde hesaplanmıştır (Bourbonniere ve Meyers, 1996). Bu değerler yüksek karbon numaralı n-alkanların baskın olduğu karasal organik maddeyi işaret etmektedir (Çizelge 2).

$P_{a q}$ oranı sualtı veya sucul bitkilerin karasal ve su yüzeyine çıkmış bitki girdisine oranını tahmin edebilmek amaciyla kullanılmaktadır (Ficken vd., 2000). $\mathrm{C}_{23}$ ve $\mathrm{C}_{25}$-alkanlar su alt1 ve yüzücü bitkilerde yaygınken, $C_{29}$ ve $C_{31}$ tipik olarak karasal bitkilerde yaygındır. $\mathrm{P}_{a q}<0.1$ olduğu durum karasal bitki girdisini yansitırken, 0.1-0.4 aralığındaki $\mathrm{P}_{a q}$ değerleri su yüzeyine çıkmış bitkileri, 0.4-1 aralığındaki $\mathrm{P}_{a q}$ değerleri ise su altı/yüzücü bitkileri yansıtır. $\mathrm{P}_{a q}$ değerleri M-4 ve M-8 nolu örnekler için sirasıyla 0.3 ve 0.7 olarak hesaplanmıştır. (Çizelge 2). M-4 örneğine ait $\mathrm{P}_{a q}$ değeri su yüzeyine çıkmış bitki girdisini işaret ederken, M-8 örneğine ait $\mathrm{P}_{a q}$ değeri su alt1/yüzücü bitki girdisini işaret etmektedir (Ficken vd., 2000). Orta ve yüksek düzeydeki $\mathrm{P}_{a q}$ değerleri su seven bitkilerin varlığını ve göreceli olarak yağışlı ve nemli bir iklimi, aynı zamanda da yüksek bir su seviyesini göstermektedir. Querol vd. (1999), çalışmalarında, Ekizköy kömür sahasının tabanında yer aldığı Sekköy formasyonunun, havzanın derinleşmesi ile yaygın kömür oluşumunun sona erdiği zaman periyodunu yansıttığından söz edilmiştir. $\mathrm{Bu}$ zaman dilimi içerisinde bölgede tektonik aktivitenin zayıfladığı, turba birikiminden dolayı göl seviyesinin hızla yükseldiği ve bu nedenle turba oluşumunun durduğu, turbanın boğulduğu belirtilmiştir. M-8 nolu örneğin alındığı üst zaman periyodu düşünüldüğünde, su altı/yüzen bitki girdisinin M-4 nolu örneğe kıyasla baskın olmasının nedeni de daha iyi anlaşılmaktadır.

$\mathrm{P}_{\text {wax }}$ değeri karasal bitkiler ve su yüzeyine çıkmış bitkiler için, turbadaki mumsu hidrokarbonların toplam hidrokarbonlara oranı baz alınarak oluşturulmuş bir parametredir. Yüksek $\mathrm{P}_{\text {wax }}$ değerleri genellikle kuru iklim şartlarındaki güçlü bir damarlı bitki girdisini işaret eder. Düşük değer ise göreceli olarak nemli iklim şartlarını yansıtır (Zheng vd., 2007). $P_{\text {wax }}$ değerleri M-4 ve M-8 nolu örneklerde sirasiyla 0.7 ve 0.5 olarak hesaplanmıştır. (Çizelge 2). $\mathrm{P}_{\text {wax }}>0.7$ olduğu durumlar soğuk-kuru k1ş iklimini yansıtmaktadır. M-4 nolu örneğin alındı̆̆ periyotta iklimin orta düzeyde nemli ve orta düzeyde sıcak olduğu, M-8 nolu örneğin alındığ 1 periyotta ise iklimin daha nemli ve 1lıman olduğu düşünülebilir. Aynı zamanda bu örneklerin $\mathrm{P}_{a q}$ değerlerine bakıldığında M-8 nolu örneğin sucul bitki girdisi açısından M-4 nolu örneğe göre daha zengin olduğu ve su seviyesinin yükseldiği söylenebilir. Eskişehir Miyosen yaşlı çökellerin palinolojisi ve paleoekolojisini konu alan bir çalışmada (Şengüler ve Akkiraz, 2014), linyit içerikli tortuların palinolojik verilerinin, nemli ve sıcak iklim şartlarını işaret ettiği belirtilmiştir. 


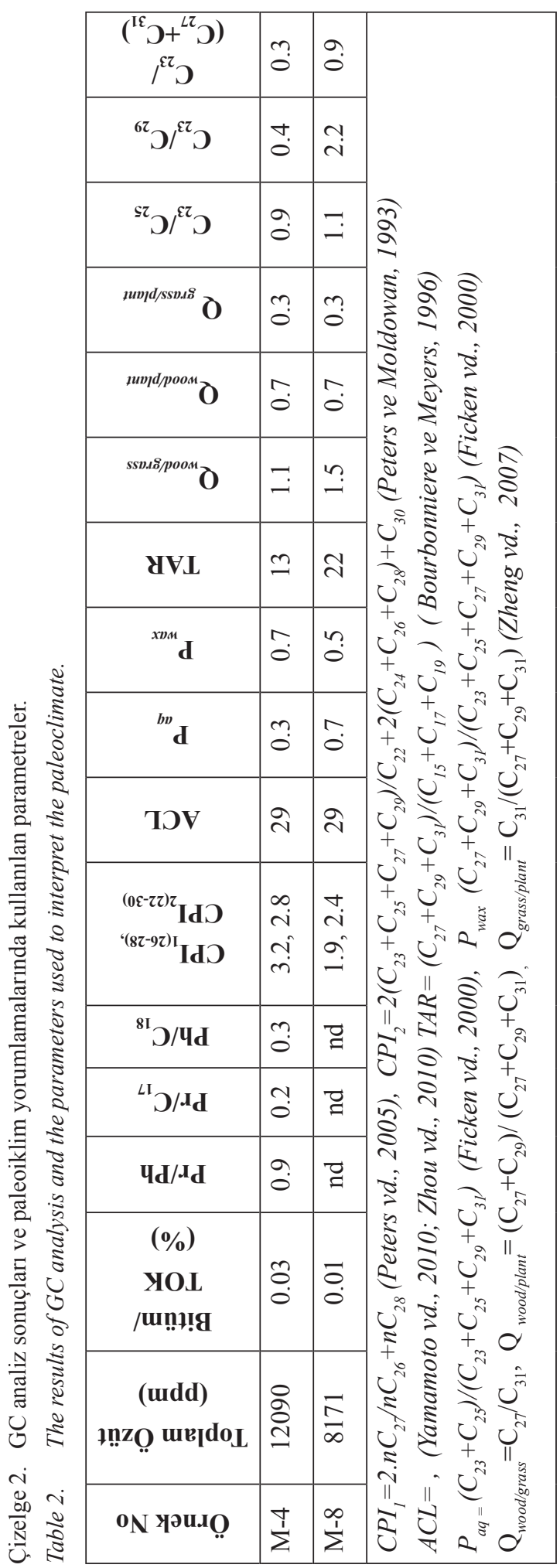

ACL (n-alkane average chain length; orta zincir uzunluklu n-alkanlar) turba oluşumu esnasındaki paleoiklimin yorumlanmasında kullanilmaktadır (Yamamoto vd., 2010; Zhou vd., 2010). Yüksek ACL değeri kuru ve soğuk iklim şartlarındaki damarlı bitki girdisinin baskınlığını yansıtmaktadır. $\mathrm{Bu}$ oran $\mathrm{M}-4$ ve M-8 nolu örneklerin her ikisinde de ortalama 29 olarak hesaplanmıştır. $\mathrm{Bu}$ değerin, orta düzeyde nem ve yağışı karakterize ettiği düşünülebilir (Hoş-Çebi ve Korkmaz, 2015).

$\mathrm{C}_{23} / \mathrm{C}_{25} \quad n$-alkan oran1, göreceli olarak daha az nemli olan yüksek alanlarda büyüyen batakl1k yosun (Spagnum) türlerinin, daha nemli çukur alanlardakine oranını göstermektedir (Bingham vd., 2010). $\mathrm{C}_{23} / \mathrm{C}_{25}$ oranlar1 $\mathrm{M}-4$ ve M-8 örneklerinde sirasiyla 0.9 ve 1.1 olarak hesaplanmıştır. $\mathrm{Bu}$ değerler bitkilerin büyüdüğü periyotta ortalama bir nemi işaret etmektedir. $\mathrm{C}_{23} / \mathrm{C}_{29}$ oran1 sucul bitki girdisinin damarl1 bitki girdisine oranını yansıtmaktadır. $\mathrm{Bu}$ oran M-4 nolu örnekte 0.4 olup damarlı bitki girdisinin egemen olduğunu, M-8 nolu örnekte ise belirlenen 2.2 değeri, egemen sucul bitki girdisini yansıtmaktadır. Aynı örneklere ait $\mathrm{P}_{a q}$ ve $\mathrm{P}_{w a x}$ değerleri de bu yorumu desteklemektedir.

$\mathrm{C}_{29}$ homologları iğne yapraklı ve yaprak dökmeyen ağaçlarda baskınken, $\mathrm{C}_{27}$ homologları geniş yapraklı ağaçlarda baskındır (Long vd., 2011). M-4 nolu örneğin GC kromatogramında $\mathrm{C}_{29}$ baskın pik iken, $\mathrm{M}-8$ nolu örneğin $\mathrm{GC}$ kromatogramında $\mathrm{C}_{27}$ nin daha baskın pik verdiği gözlenmiştir. M-4 nolu örneğin ait olduğu zaman aralığında iğne yapraklı ağaçların daha baskın, M-8 nolu örneğin ait olduğu zaman aralığında ise geniş yapraklı ağaçların daha baskın olduğu söylenebilir. 
Hoş Çebi

M-4 ve M-8 örneklerinin alındığ seviyelerdeki iklim yorumlamalarında sırasıyla ACL değerleri 29; $\mathrm{Q}_{\text {wood/grass }}, \mathrm{Q}_{\text {wood/plant }}$ ve $\mathrm{Q}_{\text {grass/plant }}$ oranlar1 $(1.1,1.5),(0.7,0.7)$ ve $(0.3,0.3)$ olarak hesaplanmıştır (Zheng vd., 2007). M-4 ve M-8 örneklerinin alındığı seviyelerde ağaçsı organik maddenin baskın, iklimin göreceli olarak nemli ve yarı tropik olduğu, ancak M-8 nolu örneğin alındığ1 periyotta iklimin M-4 nolu örneğin alındığ 1 periyoda nazaran daha nemli olduğu ve daha yüksek su tablasının bulunduğu buna bağlı olarak da sucul bitki açısından daha zengin olduğu söylenebilir (Çizelge 2).

\section{ORGANIK MADDE TIPİ}

Ekizköy kömürlerinin organik madde tiplerini belirlemek için $\mathrm{S}_{2}$-TOK (Langford ve Blanc-Valeron, 1990) ve Hİ-T ${ }_{\max }$ diyagramları kullanılmıştır (Mukhopadhyay vd., 1995). S S $_{2}$ TOK diyagramında incelenen örneklere ait 8 adet örneğin Tip III kerojen alanında dağıldığ 1 görülmüştür (Şekil 6). Hİ-T ${ }_{\max }$ diyagramında ise örneklerin Tip II kerojen alanında, Tip II ve Tip III kerojen sınırında ve Tip III kerojen alanında yer aldığ 1 gözlenmiştir (Şekil 7). Tip III (karasal organik madde) ve Tip II kerojenin, turba alanı ve çevresindeki kara bitkilerinin damar ve lif kütiküllerinden, polenlerden ve sporlardan kaynaklandığg düşünülmektedir (Hoş-Çebi ve Korkmaz, 2013).

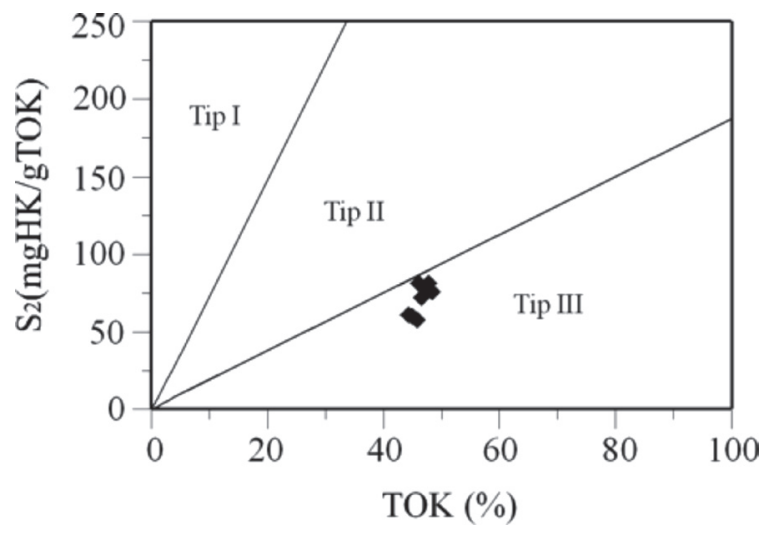

Şekil 6. Milas-Ekizköy kömür örneklerinin $\mathrm{S}_{2}$-TOK kerojen tipi diyagramındaki (Langford ve BlancValeron, 1990) dağ 11 ımı.

Figure 6. The distribution of the Milas-Ekizköy coal samples on the $S_{2}$ vs. Total Organic Carbon (TOC) kerogen type diagram (Langford and Blanc-Valeron, 1990).

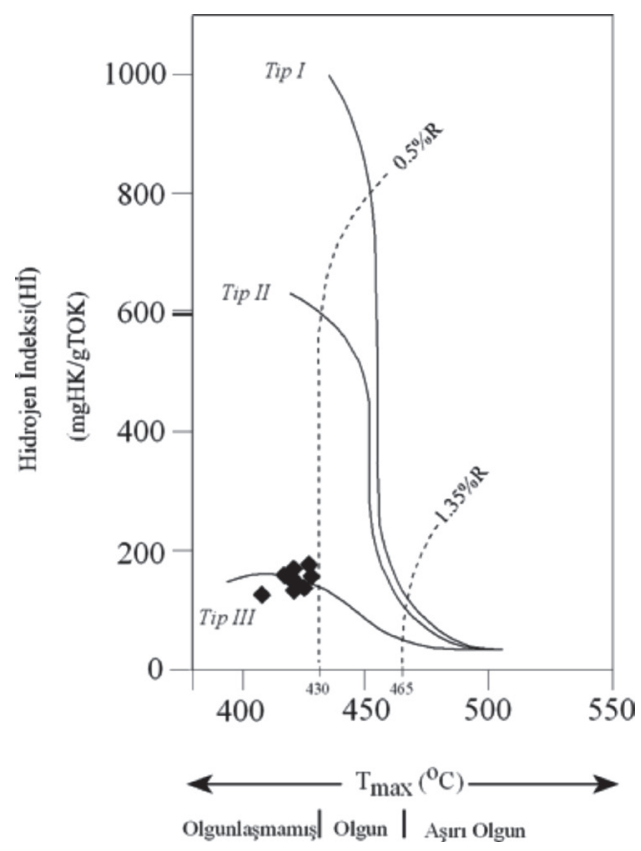

Şekil 7. Milas-Ekizköy kömür örneklerinin Hİ-T grafiğindeki (Mukhopadhyay vd., 1995) dağılımı.

Figure 7. The distribution of the Milas-Ekizköy coal samples on the HI vs. $T_{\max }$ plot graph (Mukhopadhyay et al., 1995). 


\section{OLGUNLUK}

Ekizköy kömürlerinin olgunluk yorumlamalarında, vitrinit yansıma değerlerinden (Ro\%), piroliz ve GC analiz verilerinden $\left(\mathrm{T}_{\max }\right)$ yararlanılmıştır. Vitrinit yansıması değerleri M-4 nolu örnek için 0.31 , M-8 nolu örnek için ise 0.21 aralığında ölçülmüştür. Her iki örnek de linyit aşamasındaki kömürü işaret etmektedir. Querol vd., 1991 tarafindan ise, Ekizköy sahası kömürlerinin $\mathrm{R}_{\max }$ değeri ortalama \% 0.39 olarak ölçülmüştür

Üretim İndeksi değerleri $\left(\mathrm{S}_{1} / \mathrm{S}_{1}+\mathrm{S}_{2}\right) 0.02$ ile 0.05 aralığında değişmekte olup ortalama 0.03'tür (Çizelge 1). 0.1'den küçük Üretim İndeksi değerleri olgunlaşmamış organik maddeyi göstermektedir (Merril, 1991).

Sahaya ait örneklerin $\mathrm{T}_{\max }$ değerleri 408 - $428 \mathrm{C}^{\circ}$ arasında değişmektedir. $\mathrm{T}_{\max }$ değerleri dikkate alınarak olgunluk sinıflaması yapıldığında (Peters ve Moldowan, 1993) tüm örneklerin olgunlaşmamış düzeyde olduğu görülmektedir. Organik maddenin olgunluğunu ve kerojen tipini belirlemek amaciyla $\mathrm{HI}^{-\mathrm{T}_{\text {max }}}$ diyagramı kullanılmıştır (Şekil 7). Bu diyagrama göre yine örneklerin olgunlaşmamış düzeyde olduğu görülmüştür.

Olgunlaşmamış kömürlerde, uzun zincirli $n$-alkanların k1sa zincirli $n$-alkanlara baskınlığı, karasal bitkiler ile kütiküler waxlardan kaynaklanmaktadır (Wang ve Simoneit, 1990; Bechtel vd., 2003; Eglinton ve Hamilton, 1967). CPI ve CPI değerlerinin her iki örnekte de 1'den büyük olması, Ekizköy kömürlerinin olgunlaşmamış düzeyde olduğunu göstermektedir (Çizelge 2).

\section{HIDROKARBON POTANSIYELI}

Ekizköy kömürlerinin Hİ değerleri 127$178 \mathrm{mgHK} / \mathrm{gTOK}$ arasında değişmektedir. Ortalama Hİ değeri ise $152.88 \mathrm{mgHK} / \mathrm{gTOK}$ olarak hesaplanmıştır. $150 \mathrm{mgHK} / \mathrm{gTOK}$ 'tan küçük olan Hİ değerleri ancak gaz türetebilecek bir organik maddeyi işaret etmektedir. Sahaya ait örneklerin organik madde tipleri ve $\mathrm{S}_{2} / \mathrm{S}_{3}$ kerojen tipi parametreleri hesaplandığında ortalama değerin 2 olduğu görülmüştür. $\mathrm{S}_{2} / \mathrm{S}_{3}$ kerojen tipi parametresinin 3 'ten küçük olan değerleri yalnızca gaz türetebilecek organik madde tipini işaret etmektedir (Merrill, 1991).

Ekizköy kömürlerinin Potansiyel Ürün değerleri 60.62-84.03 $\mathrm{mgHK} / \mathrm{g}$ kaya arasında değişmektedir. Ortalama Potansiyel Ürün değeri $73.02 \mathrm{mgHK} / \mathrm{g}$ kaya olarak hesaplanmıştır. Bu verilere göre Ekizköy kömürlerinin hidrokarbon potansiyellerinin yüksek olduğu, ancak Hİ değerleri ve kerojen tipi de dikkate alındığında uygun basınç ve sıcaklıkta yalnızca gaz türümü sağlayabilecek bir potansiyele sahip oldukları sonucuna varılmıştır.

\section{ORTAMSAL YORUM}

Denizel olmayan koşullarda da sülfür içeriği yüksek olabilmektedir (Bechtel vd., 2003). Markic ve Sachsenhofer (1997)'ye göre; göreceli olarak yüksek sülfür içeriği ve değişkenliği, kalsiyumca zengin yüzey sularının ve değişen $\mathrm{pH}$ değerlerinin bir sonucudur. Kömür damarlarının, kireçtaşları ve sapropelik malzemeler tarafindan üzerlenmesi, damarlardaki sülfür içeriğinin artmasına neden olmaktadır (Bechtel vd., 2001). Tatlı sulu göllerde, organik madde içinde sülfür birliktelikleri için uygun şartların olduğu bilinmektedir (Brown ve Kenig, 2004). Yüksek 
Hoş Çebi

sülfürlü ve metanca zengin kömürlerin, zayıf asidik şartlardan-nötr şartlara kadar sülfat üreten (hafif tuzlu, ac1 sulu) ortamlardaki anaerobik bakterilerin yüksek aktivitesi nedeniyle oluştuğu düşünülmektedir (Sachsenhofer vd., 2000 a,b).

Denizle irtibatlı olmayan ortamlarda oluşan kömürlerdeki yüksek kükürt içeriği, turbanın depolanma ortamındaki yüksek $\mathrm{pH}$ ve düşük $\mathrm{Eh}$ şartlarındaki yüksek su tablası ile ilişkili olabilir (Stach vd., 1982; Robert, 1980). Bu şartlarda, organik kükürt ve sinjenetik (eş zamanlı) piritin, yüksek miktarda bakteriyel aktivitelerden ve bol miktarda proteince zengin maddelerden sağlandığ1 söylenebilir. Bakteri aktivitesinin artmasıyla, kömürleri oluşturan turbada kükürt içeriğinin nispeten arttığı ifade edilmiştir (Stach vd., 1982). Biyolojik bozunma da kükürt seviyesini oldukça arttırmaktadır (Waples, 1985).

Ekizköy kömürlerinin turbalaşma sürecinde düşük bir kırıntı girdisi ve karbonatça zengin gölsel ortam şartlarının mevcut olduğu bildirilmiştir (Querol vd., 1999). Yüksek su tablası, bol mollusca faunalı göl gelişimini ve mikritik karbonat çökelimini sağlamıştır. $\mathrm{Bu}$ yüzden Ekizköy linyitleri göreceli olarak düşük $\mathrm{Al}$ ve $\mathrm{Fe}(<\% 1.4)$, yüksek sülfür $(\% 4.2)$ ve yüksek Ca (\% 6.28) içeriğine sahiptir (Querol vd., 1999). Ekizköy kömürlerinin turbalaşması esnasında yüksek pH şartları ve yüksek bakteriyal aktivite mevcuttur (Querol vd., 1999). Ekizköy kömürlerini oluşturan organik madde, çok yüksek karbonat ve sülfat içerikleri ile karakterize olan göl ortamında kapalı drenaj sistemi ve kurak-yarı kurak paleoiklim şartları altında birikmiştir (Querol vd., 1999).

Piroliz ve TOK analiz verilerinden yararlanarak oluşturulan $\mathrm{HI}_{\text {- }} \mathrm{T}_{\text {max }}$ ve $\mathrm{S}_{2}$-TOK diyagramlarında Ekizköy kömürlerinin Tip II,
Tip II ve Tip III sınırı ve Tip III kerojen alanında yer aldıkları görülmüştür. GC analizlerinden yararlanarak hesaplanan yüksek CPI ve $\mathrm{TAR}_{(H C)}$ değerleri, Ekizköy kömürlerinde karasal organik maddeyi temsil eden yüksek karbon numaralı $n$-alkanların baskın olduğunu göstermektedir.

CPI değerleri M-4 ve M-8 nolu örnekler için $\mathrm{C}_{26}-\mathrm{C}_{28}$ ve $\mathrm{C}_{22}-\mathrm{C}_{30}$ aralıklarında sırasıyla $3.2,2.8$ ve $1.9,2.4$ olarak hesaplanmıştır. Yüksek CPI değerleri göreceli olarak kuru ve soğuk paleoiklimi yansıtmakla beraber, karasal organik madde içeren kömürlerde yüksek ve tek numaralı n-alkanların baskınlığ 1 yüksek CPI değerleri vermektedir. Tüm veriler birlikte değerlendirildiğinde $\left(\mathrm{P}_{w a x}, \mathrm{P}_{a q}, \mathrm{CPI}, \mathrm{TOK}, \mathrm{ACL}\right.$, $\mathrm{Q}_{\text {wood/grass }}, \mathrm{Q}_{\text {wood/plant }} \mathrm{ve} \mathrm{Q}_{\text {grass/plant }}$ ) M-4 nolu örneğin alındığ 1 periyotta iklimin orta düzeyde nemli ve orta düzeyde sıcak olduğu, M-8 nolu örneğin alındığı periyotta ise iklimin M-4 nolu örneğin alındığı periyoda nazaran göreceli olarak daha nemli ve 1lıman olduğu düşünülebilir.

Ekizköy sahası kömürlerinin olgunluk değerlendirmesinde kullanılan ÜI, CPI, $\mathrm{CPI}_{2}$ vitrinit yansıması ve $\mathrm{T}_{\text {max }}$ değerleri olgunlaşmamış organik maddeyi işaret etmektedir.

\section{KAYNAKLAR}

Atalay, Z., 1980. Muğla ve Yatağan bölgeleri çevresindeki Neojen yaşlı kıtasal çökellerin stratigrafisi. Türkiye Jeoloji Bülteni 23/1, 93-99.

Bechtel, A., Sachsenhofer, R. F., Gratzer, R. Püttmann, W., 2001. Organic geochemical and stable carbon 1sotopic investigations of coals formed in low-lying and raised mires within the Eastern Alps (Austria). Organic Geochemistry, 32, 12891310. 
Bechtel, A., Sachsenhofer, R. F., Markic, M., Gratzer, R., Lücke, A., Püttmann, W., 2003. Palaeoenvironmental implication from biomarker and stable isotope investigations on the Pliocene Velenje lignite seam (Slovenia). Organic Gechemistry, 34, 1277-1298.

Bingham, E. M., McClymont E. L., Väliranta M., Mauquoy D., Roberts Z., Chambers F. M., Pancost R. D., Evershed R. P., 2010. Conservative composition of $n$-alkane biomarkers in Sphagnum species: implications for palaeoclimate reconstruction in ombrotrophic peat bogs. Organic Gechemistry, 41, 214-220.

Bourbonniere, R. A., Meyers, P. A., 1996. Sedimentary geolipid records of historical changes in the watersheds and productivities of Lakes Ontario and Erie. Limnology and Oceanography, 41, 352-359.

Brown, T. C., Kenig, F., 2004. Water column structure during deposition of Middle Devonian-Lower Mississipian black and gren/gray shales of the Illinois basins: a biomarker approach. Paleogeography Paleoclimate Paleoecol, 215, 59-85.

Cranwell, P. A., Eglinton G., Robinson, N., 1987. Lipids of aquatic organisms as potential contributors to lacustrine sediments-2. Organic Geochemistry, 11, 513-527.

Eglinton, G., Hamilton, R. J., 1967. Leaf epicuticular waxes. Science, 156, 1322-1335.

Ficken, K. J., Li, B., Swain, D. L., Eglinton, G., 2000. An $n$-alkane proxy for the sedimentary input of submerged/floating freshwater aquatic macrophytes. Organic Geochemistry, 31, 745749.

Goossens, H., Duren, C., De Leeuw, J. W., Schenck, P. A., 1989. Lipids and their mode ofoccurrence in bacteria and sediments-2. Lipids in the sediment of a stratified, freshwater lake. Organic Geochemistry, 14, 27-41.

Gökmen, V., Memikoğlu, O., Dağlı, M., Öz, D., Tuncali, E., 1993. Türkiye Linyit Envanteri. MTA, $356 \mathrm{~s}$.

Göktaş, F., 1982. Muğla ve çevresindeki Senozoik yaşlı çökelti kayalarının sedimantolojik ve paleontoloji araştırmalar. MTA, Arşiv No. 519, 84 s.

Görür, N., Şengör, A. M. C., Sakınç, M., Tüysüz, O., Akkök, R., Yiğitbaş, E., Oktay, F. Y., Barka, A., Sarıca, N., Ecevitoğlu, B., Demirbağ, E., Ersoy, S., Algan, O., Güneysu, C., Aykol, A., 1995. Rift formation in the Gökova region, southwest Anatolia: implications for the opening of the Aegean Sea. Geological Magazine. 132 (6) ,637-650.

Hoş-Çebi, F., Korkmaz, S., 2013. Organic geochemistry and depositional environments of Eocene coals in northern Anatolia, Turkey. Fuel, 113, 481-496.

Hoş-Çebi, F., Korkmaz S., 2015. Organic Geochemistry of Ağaçbaşı Yayla Peat Deposits, Köprübaş1/Trabzon, NE Turkey, International Journal of Coal Geology, 146, 155-165.

Hunt, J. M., 1995. Petroleum geochemistry and geology, New York: W.H. Freeman and Company; 743 p.

ICCP, 1998. The new vitrinite classification (ICCP System 1994). Fuel, 77, 349-358.

ISO 7404-5, 2009. Methods for the petrographic analysis of coals - Part 5: Method of determining microscopically the reflectance of vitrinite. Standards Australia, Level 10, The Exchange Centre 20 Bridge Street, GPO Box 476, AU-Sydney NSW 2001 (www.standards. org.au). 
Hoş Çebi

Kara-Gülbay, R., 2015. Organic geochemical and petrographical characteristics of coal bearing Oligo-Miocene sequence in the Oltu-Narman Basin (Erzurum), NE Turkey. İnternational Journal of Coal Geology, 149, 93-107.

Kayseri-Özer, M., 2013. Spatial distribution of climatic conditions from the Middle Eocene to Late Miocene based on palynoflora in Central, Eastern and Western Anatolia. Geodinamica Acta, 26, 1-2, 122-157.

Kayseri Özer, M., Akgün, F., Mayda, S., Kaya, T., 2014. Palynofloras and vertebrates from MuğlaÖren region (SW Turkey) and palaeoclimate of the Middle Burdigalian-Langhian period in Turkey. Bulletin of Geosciences, 89, 1, 137-162 pp.

Korkmaz, S., Kara Gülbay, R., 2007. Organic geochemical characteristics and depositional environments of the Jurassic coals in the eastern Taurus of Southern Turkey. International Journal of Coal Geology, 70, 292-304.

Langford, F. F., Blanc-Valleron, M. M., 1990. Interpreting rock-eval pyrolysis data using graphs of pyrozilable hydrocarbons vs. total organic carbon. AAPG Bulletin, 74, 799-804.

Long, L., Fang. X. M., Miao Y. F., Bai Y., Wang, Y. L., 2011. Northern Tibetan Plateau cooling and aridification linked to Cenozoic global cooling: Evidence from n-alkane distributions of Paleogene sedimentary sequences in the Xining Basin. Chinese Science Bulletin, 56, 1569-1578.

Markic, M., Sachsenhofer, R. F., 1997. Petrographic composition and depositional environments of the Pliocene Velenje Lignite Seam (Slovenia). International Journal of Coal Geology, 33, 229254.

Merrill, R.K., 1991. Source and Migration Processes and Evaluation Techniques (R.K. Merrill, ed.), Oklahama, $213 \mathrm{p}$.
Meyers, P. A., Ishiwatarı, R., 1993. Lacustrine organic geochemistry-an overview of indicators of organic matter sources and diagenesis in lake sediments. Organic Geochemistry, 20, 867-900.

Mukhopadhyay, P. K., Wade, J. A., Kruge, M. A., 1995. Organic facies and maturation of Jurassic/ Cretaceous rocks, and possible oil-source rock corelation based on pyrolysis of asphaltenes, Scotian Basin, Canada, OrganicGeochemistry, 22, 1, 85-104.

Querol, X., Alastuey, A., Plana, F., Lopez-Soler, A., Tuncali, E., Toprak, S., Ocakoğlu. F., Koker, B., 1999. Coal geology and coal quality of the Miyosen Muğla basin, southwestern Anatolia, Turkey, International Journal of Coal Geology, 41, 311-332.

Peters, K. E., Moldowan J. M., 1993. The Biomarker Guide: Interpreting molecular fossils in petroleum and ancient sediments. Englewood Cliffs (N.J.): Prentice-Hall, 363 p.

Peters, K. E., Walters, C. C., Moldowan, J. M., 2005. The Biomarker Guide: Biomarkers and Isotopes in Petroleum Exploration and Earth History. Cambridge University Press, 1155 p.

Petersen, H. I., Andersen, C., Anh, P. H., BojesenKoefeld, J. A., Nielsen, L. H., Nytoft, H. P., Rosenberg, P., Thanh, L., 2001. Petroleum potential of Oligocene lacustine mudstones and coals Ot Dong Ho, Vietnam - an outcrop analogue to tterrestrial source rocks in the greater Song Hong Basin. Journal of Asian Earth Sciences, $19,135-154$.

Robert, P., 1980. The Optical Evolution of Kerogen and Geothermal Histories Applied to Oil and Gas Exploration: In: Durand B., (Ed.) q.v., chapter $11,340-414$.

Sachsenhofer, R. F., Kogler, A., Polesny, H., Strauss, P., Wagreich, M., 2000a. The Neogene Fohnsdorf Basin: Basin formation and basin inversion during lateral extrusion in the Eastern Alps. 
International Journal of Earth Science, 89, 415430.

Sachsenhofer, R. F., Strauss, P., Wagreich, M., Abart, R., Decker, K., Goldbrunner, J. E., Gruber, W., Kriegl, C., Spötl, C., 2000b. Das Miozäne Fohnsdorfer Becken-Eine Übersicht. Mitt. Ges. Geol. Bergbaustud. Österr, 4, 173-190.

Stach, E., Mackowsky, M.-Th., Teichmüller, M., Taylor, G. H., Chandra, D., Teichmüller, R., 1982. Stach's Textbook of Coal Petrology, Gebrüder Borntraeger, Berlin, 535 p.

Stout, S. A., 1992. Aliphatic ve aromatic triterpenoid hydrocarbons in a Tertiary angiospermous lignite. Organic Geochemistry, 18, 51-66.

Şengüler, İ., Akkiraz, M. S., 2014. Eskişehir havzasındaki Miyosen yaşlı tortulların palinolojisi ve paleoekolojisi. TPJD Bülteni, 26 (1), 7-17.

Tissot, B. P., Welte, D. H., 1984. Petroleum Formation and Occurence, Springer Verlag, Berlin, Heidelberg, New York Tokyo, 699 p.

Volkman, J. K., 1986. A review of sterolmarkers formarine and terrigenous organicmatter. Organic Geochemistry, 9, 83-99.

Walters, C. C., Cassa, M. R., 1985. Regional Organic Geochemistry of offshore Louisiana. Transactions Gulf Coast Association Geological Society, 35, 277-286.

Wang, T. G., Simoneit, B. R. T., 1990. Organic geochemistry and coal petrology of Tertiary brown coal in the Zhoujing Mine, Baise Basin, South China. Fuel, 69, 12-20.

Waples, D. W., 1985. Geochemistry in Petroleum Exploration: International Human Resources Development Corporation, Boston, 232 p.

Xie, S., Nott, C. J., Avsejs, L. A., Maddy, D., Chambers, F., Evershed, R. P., 2004. Molecular and isotopic stratigraphy in an ombrotrophic mire for palaeoclimate reconstruction. Geochimica et Cosmochimica Acta, 68, 2849-2862.
Yalçın Erik, N., Ay, F., 2010. Tersiyer yaşlı Artova ve Zile kömürlerinin (Tokat) organik jeokimyasal özellikleri ve hidrokarbon türetim potansiyelleri. Hacettepe Üniversitesi Yerbilimleri Uygulama ve Araştırma Merkezi Dergisi, 31 (3), 169-190.

Yalçın Erik, N., Sancar, S., 2010. Relationship between coal-quality and organic-geochemical parameters: a case study of the Hafik Coal Deposits (Sivas Basin, Turkey). International Journal Of Coal Geology, 83, 396-414.

Yalçın Erik, N., Ay, F., 2013. Organic geochemical characterization and hydrocarbon potential of Tertiary coals Of The Tokat Province (Central Anatolia, Turkey). Energy Sources, Part A, 35, 991-999.

Yalçın Erik, N., 2016, Paleoenvironment characteristics and hydrocarbon potential of the Lower Miocene Bituminous shales in Sivas Basin (Central Anatolia, Turkey). Journal of Arabian Earth Science, 9,18.

Yamamoto, S., Kawamura, K., Seki, O., Meyers, P. A., Zheng, Y., Zhou, W., 2010. Environmental influences over the last $16 \mathrm{ka}$ on compoundspecific d13C variations of leaf wax $n$-alkanes in the Hani peat deposit from northeast China. Chemical Geology, 277, 261-268.

Yiğitel, I., 1979. Güneybatı Anadolu'da yer alan sahaların genel görünümü, MTA raporu, No: 6180, Ankara, yayımlanmamış, $15 \mathrm{~s}$.

Zhang, E., Hatcher, P. G., Davis, A., 1993. Chemical composition of pseudo-phlobaphinite precursors: Implications for the presence of aliphatic biopolymers in vitrinite from coal. Organic Geochemistry, 20, 721-734.

Zheng, Y., Zhou, W., Meyers, P. A., Xie, S., 2007. Lipid biomarkers in the Zoigê-Hongyuan peat deposit: Indicators of Holocene climate changes in West China. Organic Geochemistry, 38, 19271940. 
Hoş Çebi

Zhou, W., Xie, S., Meyers, P. A., Zheng, Y., 2005. Reconstruction of late glacial holocene climate evolution in southern China from geolipids and polen in the Dingnan peat sequence. Organic Geochemistry, 36, 1272-1284.
Zhou, W., Zheng, Y., Meyers, P. A., Jull, A. J. T., Xie, S., 2010. Postglacial climate-change record in biomarker lipid compositions of the Hani peat sequence, northeastern China. Earth and Planetary Science Letters, 294, 37-46. 